\title{
Avaliação do uso de fertilizantes organominerais e químicos na fertirrigação do cafeeiro irrigado por gotejamento ${ }^{1}$
}

\author{
André L. T. Fernandes ${ }^{2}$, Roberto Santinato ${ }^{3}$, Luís C. D. Drumond ${ }^{2}$ \& Clênio B.de Oliveira ${ }^{4}$
}

\begin{abstract}
RESUMO
Com o objetivo de avaliar a fertirrigação do cafeeiro com a utilização de diferentes fontes de fertilizantes, instalou-se um experimento na Fazenda Escola da Universidade de Uberaba, em Latossolo Vermelho Amarelo textura arenosa, a $850 \mathrm{~m}$ de altitude, em lavoura de café Catuaí Vermelho IAC 144. Foram aplicados os seguintes tratamentos: adubação de cobertura convencional química; adubação de cobertura com adubos sólidos convencionais, via fertirrigação; adubação de cobertura com adubos próprios para fertirrigação, de alta solubilidade; adubação de cobertura com fertilizantes organominerais sólidos, produzidos com resíduos orgânicos enriquecidos com minerais e adubação de cobertura com fertilizantes organominerais líquidos. Para efeito de comparação, mantiveram-se, para os diferentes tratamentos, as mesmas doses de $\mathrm{N}, \mathrm{P}_{2} \mathrm{O}_{5}$ e $\mathrm{K}_{2} \mathrm{O}$. Após quatro safras, concluiu-se que as fontes de fertilizantes utilizadas, tanto em fertirrigação quanto na aplicação convencional no solo, não apresentaram diferenças significativas em termos de produtividade do cafeeiro. Com relação à qualidade final do café avaliada após análise sensorial da bebida obtida pelos diferentes tratamentos, também não se verificaram diferenças significativas entre os tratamentos.
\end{abstract}

Palavras-chave: nutrição mineral e orgânica, café, quimigação

\section{Evaluation of use of chemical and organic fertilizers through fertigation in drip irrigated coffee crop}

\begin{abstract}
In order to evaluate coffee fertigation using different sources of mineral fertilizers and organic, comparing with conventional application, an experiment was installed in the Experimental Field "Fazenda Escola", Uberaba in the State of Minas Gerais, Brazil, in a sandy soil, $850 \mathrm{~m}$ of altitude, with coffee "Catuaí Vermelho IAC 144". The following treatments were applied: chemical conventional top dressing; top dressing with conventional fertilizers, through fertigation; top dressing manuring with appropriate fertilizers for fertigation; solid organomineral fertilizers, through soil and liquid organomineral fertilizers, through fertigation. For comparison purposes, the same amounts of $\mathrm{N}, \mathrm{P}_{2} \mathrm{O}_{5}$ and $\mathrm{K}_{2} \mathrm{O}$ were maintained for the different treatments. Irrigation control was accomplished by using a automatic weather station. After four harvests, it may be concluded that the sources of fertilizers used, in fertigation and in conventional application in the soil, did not show significant effects in coffee yield. Regarding the final quality of the coffee, appraised by the sensorial test in different treatments. No significant differences were verified among the treatments.
\end{abstract}

Key words: organic and mineral nutrition, coffee, quimigation

1 Projeto de pesquisa financiado, em parte, com recursos do Consórcio Brasileiro de Pesquisa e Desenvolvimento do Café, Embrapa/Café ${ }^{2}$ Universidade de Uberaba, Av. Nenê Sabino 1801 - Bloco R, CEP 38055-500, Uberaba, MG. Fone: (34) 3319-8963. E-mail: andre.fernandes@uniube.br ${ }^{3}$ Ministério da Agricultura - Regional Campinas, Av. Heitor Penteado s/n, Lago do Café, CEP 13087-000. Campinas, SP. Fone: (19) 3256-0200, E-mail: marecam@terra.com.br ${ }^{4}$ Fazenda Escola da Universidade de Uberaba, Rodovia BR 050, Km 45, Uberaba, MG, Fone: (34) 3359-0157 


\section{INTRODUÇÃO}

A irrigação do cafeeiro tem recebido grande destaque nos últimos anos, cujo interesse se deve a vários fatores, dentre os quais se destacam: expansão da cafeicultura para novas fronteiras; evolução da técnica da irrigação; diminuição dos custos dos sistemas de irrigação e mentalidade do cafeicultor no sistema de produção café, priorizando a eficiência e a qualidade da produção (Mantovani \& Soares, 2003; Santinato \& Fernandes, 2002). O efeito da irrigação no crescimento vegetativo e na produção do cafeeiro, e a melhoria na qualidade da sua produção são bem documentados na literatura podendo-se, ainda, utilizar esta técnica como condicionante do florescimento e, portanto, da época de colheita (Camargo \& Pereira, 1994).

Dentre os sistemas de irrigação do cafeeiro destaca-se o gotejamento, por suas vantagens de economia de água e energia e alta eficiência na aplicação de água. A introdução, no País, de sistemas de irrigação por gotejamento na cultura do café, em escala comercial, ocorreu no início da década de 90. Na segunda metade desta década, os sistemas de gotejamento se popularizaram e sua aplicação em lavouras de café cresceu de forma significativa (Silva et al., 2003). Estima-se que aproximadamente 15 a 20 mil hectares de café estejam sendo irrigados por gotejamento no Brasil (AGRIANUAL, 2002). Para que a irrigação seja uma prática viável, torna-se necessário adotar práticas que contribuam para o aumento da produtividade e do lucro. Uma destas práticas é a fertirrigação, que tem sido utilizada com freqüência pelos cafeicultores irrigantes, em especial por aqueles que dispõem de sistemas de irrigação por pivô central e gotejamento.

Com base em resultados de pesquisas e na experiência de agricultores, o uso combinado de fertilizantes na água de irrigação apresenta vantagens e limitações, no que diz respeito à sua aplicação. As principais vantagens no uso da fertirrigação, segundo Frizzone et al. (1985), Costa et al. (1986), Hernandez (1993) são: a) melhor aproveitamento dos equipamentos de irrigação; b) economia de mão-de-obra; c) distribuição uniforme e localizada dos fertilizantes; d) aplicação de adubo em qualquer fase de desenvolvimento da cultura; e) eficiência do uso e economia de fertilizantes; f) redução da compactação do solo e dos danos mecânicos à cultura; g) controle da profundidade de aplicação; h) possibilidade de aplicação de micronutrientes.

Com relação às limitações, a maioria dos inconvenientes citados na literatura não se deve à fertirrigação em si mas, ao problema de manejo incorreto e à falta de informações com relação a muitos aspectos ligados à nutrição das plantas. Segundo Loomis \& Connor (1992) plantas cultivadas absorvem menos da metade do fertilizante aplicado, podendo o restante ser carreado para águas superficiais ou subterrâneas, permanecer adsorvidos aos colóides do solo ou contribuir para a poluição atmosférica.

Em experimento conduzido em Rio Preto, MG, Antunes et al. (2000), estudando o efeito da irrigação e da fertirrigação na produção do cafeeiro Catuaí Vermelho, com oito anos de idade verificaram superioridade de $66 \%$ do tratamento irriga- do em relação à testemunha não irrigada e 123\% de superioridade dos tratamentos fertirrigados.

Em trabalho desenvolvido em Lavras, região sul de Minas Gerais, Silva et al. (2003) avaliaram os custos de produção do cafeeiro Acaiá Cerrado, cultivado no espaçamento 3,0 x 0,6 $\mathrm{m}$ submetido a diferentes lâminas de irrigação e a 3 parcelamentos de nitrogênio e potássio (3, 6 e 9 vezes). Os autores concluíram, após 3 safras, que os insumos (fertilizantes químicos, matéria orgânica, defensivos, espalhante adesivo, herbicidas e micronutrientes) foram os que mais afetaram o custo de produção, com gastos de, em média, $\mathrm{R} \$ 6.437,35 \mathrm{ha}^{-1}$ (ou $25 \%$ dos gastos totais). Para Costa et al. (1986), a falta de informações, principalmente sobre doses, tipos de fertilizante mais recomendados, prevenção à formação de precipitados, modo e época de aplicação, reflete necessidade de pesquisas nesta área.

Dentro deste contexto, o trabalho teve por objetivo avaliar a eficiência de diferentes fertilizantes, sejam eles minerais convencionais, minerais de alta solubilidade e organominerais, sólidos e líquidos, no desenvolvimento vegetativo e na produção do cafeeiro arábica, cultivado em condições de cerrado (Uberaba, MG), comparando-se com a adubação química convencional de cobertura.

\section{MATERIAL E MÉTODOS}

O experimento foi instalado no Campus Experimental da Universidade de Uberaba - Fazenda Escola, na cidade de Uberaba, MG, cujas coordenadas geográficas são: latitude $19^{\circ}$ 44 ' 13 'S, longitude $47^{\circ} 57^{\prime} 27^{\prime}$ " W e altitude de $850 \mathrm{~m}$, em um solo classificado como Latossolo Vermelho Amarelo, distrófico, com teores de areia de $72,64 \%$, argila de $21,96 \%$ e silte de $5,4 \%$. O cultivar de café utilizado foi o Catuaí IAC 144, plantada em dezembro de 1998, no espaçamento de 4,0 x 0,5 m. O clima de Uberaba é classificado, pelo método de Köppen, como Aw, tropical quente e úmido, com inverno frio e seco. A precipitação pluviométrica anual é de $1474 \mathrm{~mm}$ e a temperatura média anual é de $22,6^{\circ} \mathrm{C}$. O sistema de irrigação utilizado no experimento foi por gotejamento com emissores de vazão de 2,3 $\mathrm{L} \mathrm{h}^{-1}$, espaçados 4,0 m entre linhas e $0,70 \mathrm{~m}$ entre plantas.

Antes do início do experimento procedeu-se à avaliação do sistema de irrigação, para determinação da uniformidade de aplicação de água. Determinaram-se o coeficiente de uniformidade de emissão e o coeficiente de uniformidade estatística. Esta análise foi repetida anualmente, para verificação das condições de funcionamento do sistema de gotejamento em cada tratamento. A vazão média dos gotejadores utilizados no experimento após as avaliações de campo foi de 2,2 $\mathrm{L} \mathrm{h}^{-1}$, e os coeficientes médios encontrados foram de 95,0 e $94,7 \%$, respectivamente, para a uniformidade estatística e a uniformidade de emissão, o que permite concluir que o sistema operava de forma extremamente satisfatória, sobretudo para a prática da fertirrigação.

Para a análise da água utilizada no experimento retiraramse amostras no reservatório da fazenda (açude), e se fizeram análises das características físicas, organolépticas, biológicas, 
químicas, bacteriológicas e de metais pesados (Tabela 1). De acordo com a Resolução n ${ }^{\circ} 20$, de 18 de junho de 1986, do Conselho Nacional do Meio Ambiente (CONAMA, 1986), esta água é classificada como classe 3, e pode ter, como usos recomendados: a) abastecimento doméstico, após tratamento convencional; b) irrigação de culturas arbóreas, cerealíferas e forrageiras e c) dessedentação de animais. Comparando-se os valores de sólidos suspensos, sólidos totais e quantidade de ferro, classifica-se a água como de baixo risco de obstrução de gotejadores (Pizarro, 1990).

Antes do início do experimento coletaram-se amostras de solo em cada parcela, que foram submetidas a análise. As análises de solo foram repetidas anualmente. As características físico-hídricas do solo do experimento são apresentadas na Tabela 2, e as características químicas na Tabela 3 , onde estão dispostas as médias das análises de cada parcela, por profundidade.

Tabela 1. Resultado da análise da água utilizada no experimento

\begin{tabular}{|c|c|c|}
\hline Características & Unidades & Resultados \\
\hline \multicolumn{3}{|c|}{ Físicas e organolépticas } \\
\hline Temperatura & ${ }^{\circ} \mathrm{C}$ & 25 \\
\hline Cor & $m g ~ p t L^{-1}$ & 25 \\
\hline Turbidez & FTU & 4,3 \\
\hline Sólidos totais & $\mathrm{mg} \mathrm{L}^{-1}$ & 65 \\
\hline Sólidos voláteis & $\mathrm{mg} \mathrm{L}^{-1}$ & 44 \\
\hline Sólidos fixos & $\mathrm{mg} \mathrm{L}^{-1}$ & 21 \\
\hline Sólidos sedimentáveis & $\mathrm{mg} \mathrm{L}^{-1} \mathrm{em} 60^{\prime}$ & $<1$ \\
\hline Sólidos suspensos & $\mathrm{mg} \mathrm{L}^{-1}$ & 31 \\
\hline \multicolumn{3}{|c|}{ Biológicas } \\
\hline DBO & $m g L^{-1}$ & 2 \\
\hline DQO & $\mathrm{mg} \mathrm{L}^{-1}$ & 9 \\
\hline \multicolumn{3}{|c|}{ Químicas } \\
\hline $\mathrm{pH}$ & $\mathrm{pH}$ & 8,0 \\
\hline Condutividade elétrica & $\mathrm{dS} \mathrm{m}^{-1}$ & 0,8 \\
\hline Oxigênio dissolvido & $\mathrm{mg} \mathrm{L}^{-1}$ & 7,2 \\
\hline Fósforo total & $\mathrm{mg} \mathrm{L}^{-1}$ & 0,6 \\
\hline Nitrogênio amídico & $\mathrm{mg} \mathrm{L}^{-1}$ & 1,2 \\
\hline Nitrogênio amoniacal & $\mathrm{mg} \mathrm{L}^{-1}$ & 0,7 \\
\hline Ferro total & $\mathrm{mg} \mathrm{L}^{-1}$ & 0,1 \\
\hline Alcalinidade total & $\mathrm{mg} \mathrm{L}^{-1}$ & 73 \\
\hline Dureza total & $\mathrm{mg} \mathrm{L}^{-1}$ & 38 \\
\hline Dureza cálcica & $\mathrm{mg} \mathrm{L}^{-1}$ & 31 \\
\hline Dureza magnesiana & $\mathrm{mg} \mathrm{L}^{-1}$ & 7 \\
\hline \multicolumn{3}{|c|}{ Bacteriológicas } \\
\hline Microorganismos totais & MP (colônias $\mathrm{mL}^{-1}$ ) & 250 \\
\hline \multicolumn{3}{|c|}{ Metais pesados } \\
\hline Chumbo & $\mathrm{mg} \mathrm{L}^{-1}$ & 0,001 \\
\hline Mercúrio & $\mathrm{mg} \mathrm{L}^{-1}$ & 0,001 \\
\hline Arsênio & $\mathrm{mg} \mathrm{L}^{-1}$ & $<0,001$ \\
\hline Cobre & $\mathrm{mg} \mathrm{L}^{-1}$ & 0,451 \\
\hline Cádmio & $\mathrm{mg} \mathrm{L}^{-1}$ & 0,001 \\
\hline Zinco & $\mathrm{mg} \mathrm{L}^{-1}$ & 0,001 \\
\hline
\end{tabular}

Tabela 2. Características físico-hídricas do solo do experimento

\begin{tabular}{lc}
\hline Características & Valor \\
Areia & $72,60 \%$ \\
\hline Silte & $5,40 \%$ \\
\hline Argila & $21,96 \%$ \\
\hline Ponto de murcha permanente & $0,132 \mathrm{~cm}^{3} \mathrm{~cm}^{-3}$ \\
\hline Capacidade de campo & $0,213 \mathrm{~cm}^{3} \mathrm{~cm}^{-3}$ \\
\hline Água disponível & $0,081 \mathrm{~cm}^{3} \mathrm{~cm}^{-3}$ \\
\hline Densidade aparente do solo & $1,47 \mathrm{~kg} \mathrm{dm}^{-3}$ \\
\hline
\end{tabular}

O fertilizante organomineral, tanto sólido quanto líquido, foi produzido na Fábrica Piloto localizada na Fazenda Escola. A matéria-prima utilizada para sua fabricação foi serragem de pinus, composto de lixo urbano e cama de frango produzida na fazenda. Esta matéria-prima passou por um processo de desodorização, desinfecção e transformação biológica (compostagem).

Ao longo de 4 anos, foram aplicados os seguintes tratamentos, após a formação da lavoura: 1) T1 - Fertirrigação com adubos altamente solúveis: adubo solúvel mineral 20-05-20 em 16 aplicações, via água de irrigação, com as fontes nitrato de potássio e MAP purificado; 2) T2 - Fertirrigação com adubos convencionais: adubo químico 20-05-20 em 16 aplicações, via água de irrigação, com as fontes uréia, sulfato de amônio, cloreto de potássio e MAP; 3) T3 - Fertirrigação com adubos organominerais líquidos: adubo 16-02-16, em 16 aplicações, via fertirrigação; 4) T4 - Adubação convencional via solo, com fontes minerais: adubo químico 20-05-20 $\left(\mathrm{N}-\mathrm{P}_{2} \mathrm{O}_{5}-\mathrm{K}_{2} \mathrm{O}\right)$ em 04 aplicações, com as fontes uréia, sulfato de amônio, cloreto de potássio e MAP; 5) T5 -Adubação convencional via solo com fontes organominerais: adubo 02-02-02 em 4 aplicações. Para efeito de comparação mantiveram-se, para os diferentes tratamentos, as mesmas doses de $\mathrm{N}, \mathrm{P}_{2} \mathrm{O}_{5}$ e $\mathrm{K}_{2} \mathrm{O}$, com adubações anuais equivalentes a $450 \mathrm{~kg}$ de N, $100 \mathrm{~kg}$ de $\mathrm{P}_{2} \mathrm{O}_{5}$ e $400 \mathrm{~kg}$ de $\mathrm{K}_{2} \mathrm{O} \mathrm{ha}{ }^{-1}$. Os fertilizantes foram injetados via água de irrigação com a utilização de um injetor tipo Venturi 3/4", com capacidade de injeção de até $250 \mathrm{~L} \mathrm{~h}^{-1}$.

$\mathrm{O}$ delineamento experimental utilizado foi o inteiramente ao acaso, com 5 tratamentos e 3 repetições, totalizando 15 parcelas experimentais de $100 \mathrm{~m}$, com 200 pés de café escolhendo-se, ao acaso, 10 plantas em cada parcela, para as medidas de: a) diâmetro do caule a $15 \mathrm{~cm}$ de altura (a cada 3 meses, até a primeira produção); b) altura da planta (a cada 3 meses, até a primeira produção) e produtividade (anual).

Para o acompanhamento do estado nutricional das plantas nos diferentes tratamentos, realizou-se a diagnose foliar na época de granação dos frutos (janeiro e fevereiro de cada ano). Coletaram-se 50 folhas de cada parcela, de 20 plantas de café, obtidas ao acaso, dos terceiro e quarto pares, em ramos produtivos situados na altura média do cafeeiro dos dois lados da linha do café, segundo recomendações de van Raij et al. (1997). As folhas, após devidamente acondiciona- 
Tabela 3. Resultados da análise química do solo, para os diferentes tratamentos, em duas profundidades, médias após quatro anos de experimento.

\begin{tabular}{|c|c|c|c|c|c|c|c|c|c|c|}
\hline \multirow{2}{*}{ Tratamentos ${ }^{(1)}$} & \multirow{2}{*}{$\mathrm{pH}$} & Al & $\mathrm{Ca}$ & $\mathrm{Mg}$ & SB & $t$ & K & $\mathbf{P}$ & \multirow{2}{*}{$\begin{array}{l}\mathbf{V} \\
\%\end{array}$} & \multirow{2}{*}{$\begin{array}{c}\text { M.O } \\
\text { dag } \mathbf{k g}^{-1}\end{array}$} \\
\hline & & \multicolumn{4}{|c|}{$\mathrm{cmol}_{\mathrm{c}} \mathrm{dm}^{-3}$} & & \multicolumn{2}{|c|}{$\mathrm{mg} \mathrm{dm^{-3 }}$} & & \\
\hline & \multicolumn{10}{|c|}{ Profundidade de $0-20 \mathrm{~cm}$} \\
\hline $\mathrm{T} 1$ & 5,5 & 0,1 & 1,5 & 0,7 & 2,3 & 2,4 & 47 & 52 & 53,7 & 1,2 \\
\hline $\mathrm{T} 2$ & 5,0 & 0,5 & 1,0 & 0,4 & 1,5 & 2,0 & 41 & 17 & 37,6 & 1,0 \\
\hline T3 & 4,9 & 0,5 & 0,7 & 0,5 & 1,4 & 1,9 & 65 & 10 & 35,3 & 1,0 \\
\hline T4 & 5,6 & 0,1 & 1,8 & 0,8 & 2,7 & 2,8 & 55 & 56 & 54,4 & 1,4 \\
\hline \multirow[t]{2}{*}{ T5 } & 5,7 & 0,1 & 1,7 & 0,9 & 2,8 & 2,9 & 80 & 66 & 60,9 & 1,2 \\
\hline & \multicolumn{10}{|c|}{ Profundidade de $20-40 \mathrm{~cm}$} \\
\hline $\mathrm{T} 1$ & 5,0 & 0,5 & 1,0 & 0,3 & 1,4 & 1,9 & 29 & 8 & 37,4 & 1,0 \\
\hline T2 & 4,7 & 0,7 & 0,6 & 0,3 & 1,0 & 1,7 & 44 & 2 & 28,8 & 0,7 \\
\hline T3 & 4,8 & 0,7 & 0,5 & 0,4 & 1,1 & 1,8 & 65 & 1 & 29,9 & 1,0 \\
\hline T4 & 4,9 & 0,7 & 0,9 & 0,4 & 1,4 & 2,1 & 34 & 40 & 34,8 & 1,0 \\
\hline $\mathrm{T} 5$ & 5,1 & 0,4 & 1,1 & 0,3 & 1,6 & 2,0 & 60 & 10 & 46,3 & 0,7 \\
\hline
\end{tabular}

(1) T1 - Fertirrigação com adubos altamente solúveis;

T2 - Fertirrigação com adubos convencionais;

T3 - Fertirrigação com adubos organominerrais líquidos

T4 - Adubação convencional via solo com fontes minerais

T5 - Adubação convencional via solo com fontes organominerais

$\mathrm{SB}$ - soma de bases trocáveis $[\mathrm{Ca}+\mathrm{Mg}+(\mathrm{K} / 390)]$

$\mathrm{t}-\mathrm{CTC}$ efetiva

$\mathrm{V}$ - saturação por bases

das em envelopes de papel, foram enviadas imediatamente ao laboratório para análise química.

O controle da irrigação foi realizado a partir dos dados obtidos de uma estação agrometeorológica. Através das medidas obtidas pelos sensores (temperatura, umidade relativa, velocidade de vento e radiação solar), estimou-se a evapotranspiração da cultura pelo método de Penman Monteith. Este método é uma adaptação do modelo original de Penman, introduzindo os conceitos de resistência do dossel $\left(\mathrm{r}_{\mathrm{c}}\right)$ e de resistência aerodinâmica $\left(\mathrm{r}_{\mathrm{a}}\right)$ (Monteith, 1965), e é recomendado pela FAO, segundo Smith (1991).

Durante o período do ensaio verificaram-se valores de deficiência hídrica anual de 209 e $146 \mathrm{~mm}$ para os anos de 2001 e 2002 e excedente hídrico de 615 e $527 \mathrm{~mm}$, respectivamente para os anos de 2003 e 2004.

Para determinação do tempo de irrigação, consideraram-se a vazão do emissor, o espaçamento entre emissores, o espaçamento entre linhas laterais e um fator de ajuste relacionado à redução da área molhada, por se tratar de irrigação localizada. A evapotranspiração da cultura (ETc) foi estimada pela Eq. 1:

$$
\mathrm{ET}_{\mathrm{c}}=\mathrm{ET}_{0} \cdot \mathrm{K}_{\mathrm{c}} \cdot \mathrm{K}_{\mathrm{m}}
$$

em que:

$\mathrm{ET}_{\mathrm{o}}$ - Evapotranspiração de referência, estimada pela equação de Penman Monteith, $\mathrm{mm} \mathrm{d}^{-1}$;

$\mathrm{K}_{\mathrm{c}}$ - coeficiente de cultura, adimensional (Tabela 4)

$\mathrm{K}_{\mathrm{m}}$ - fator de ajuste da evapotranspiração para microirrigação, adimensional, calculado pela Eq. 2.

$$
\mathrm{K}_{\mathrm{m}}=\sqrt{\mathrm{As}}
$$

em que:

As - fração da área sombreada pela cultura ao meio dia, adimensional

\begin{tabular}{|c|c|c|}
\hline $\begin{array}{l}\text { Idade da planta } \\
\text { (anos) }\end{array}$ & $\begin{array}{c}\text { Espaçamento entre ruas }(\mathrm{m}) \mathrm{X} \text { Espaçamento } \\
\text { entre plantas }(\mathrm{m})\end{array}$ & Kc \\
\hline \multirow{4}{*}{$\begin{array}{l}\text { 1. Lavoura adulta } \\
\text { (mais de } 3 \text { anos) }\end{array}$} & $>3,0 x>1,0\left(2500\right.$ plantas ha $\left.^{-1}\right)$ & 1,0 \\
\hline & $>3,0 \times 0,5$ a $1,0\left(3.333\right.$ plantas ha $\left.^{-1}\right)$ & 1,1 \\
\hline & $2 \mathrm{a}<3 \times 0,5$ a 1,0 (6.666 plantas ha $\left.^{-1}\right)$ & 1,2 \\
\hline & $1 \mathrm{a}<2 \times 0,5$ a $1,0\left(13.333\right.$ plantas ha $\left.^{-1}\right)$ & 1,3 \\
\hline \multirow{4}{*}{$\begin{array}{l}\text { 2. Lavoura nova (de } \\
1 \text { a } 3 \text { anos) }\end{array}$} & $>3,0 x>1,0\left(2500\right.$ plantas ha $\left.^{-1}\right)$ & 0,8 \\
\hline & $>3,0 \times 0,5$ a $1,0\left(3.333\right.$ plantas ha $\left.^{-1}\right)$ & 0,9 \\
\hline & $2 \mathrm{a}<3 \times 0,5$ a 1,0 ( 6.666 plantas ha $\left.^{-1}\right)$ & 1,0 \\
\hline & $1 \mathrm{a}<2 \times 0,5$ a $1,0\left(13.333\right.$ plantas ha $\left.^{-1}\right)$ & 1,1 \\
\hline \multirow{4}{*}{$\begin{array}{l}\text { 3. Lavoura nova } \\
\text { (até } 1 \text { ano) }\end{array}$} & $>3,0 x>1,0\left(2500\right.$ plantas ha $\left.^{-1}\right)$ & 0,6 \\
\hline & $>3,0 \times 0,5$ a $1,0\left(3.333\right.$ plantas ha $\left.^{-1}\right)$ & 0,7 \\
\hline & $2 \mathrm{a}<3 \times 0,5$ a $1,0\left(6.666\right.$ plantas ha $\left.^{-1}\right)$ & 0,8 \\
\hline & $1 \mathrm{a}<2 \times 0,5$ a $1,0\left(13.333\right.$ plantas $\left.\mathrm{ha}^{-1}\right)$ & 0,9 \\
\hline
\end{tabular}

Tabela 4. Coeficiente de cultura (Kc) do café

Os tratos fitossanitários foram idênticos entre os tratamentos realizando-se, semanalmente, uma avaliação da infestação de doenças e pragas. A aplicação dos produtos sistêmicos para controle da ferrugem e bicho-mineiro, foi realizada por quimigação, através do injetor tipo venturi.

A colheita foi realizada aos 30, 42, 54 e 66 meses, sendo colhidas 10 plantas ao acaso por parcela, quando a porcentagem de frutos verdes foi inferior a 5\%, conforme recomendação de Teixeira \& Gomes (1970). Os valores de litros de café colhido por pé foram convertidos em sacas beneficiadas de $60 \mathrm{~kg}$, utilizando-se um fator de rendimento de colheita (relação entre a quantidade de café colhido e a quantidade de café após o beneficiamento).

Para avaliação da qualidade final da bebida obtida com os diferentes tratamentos irrigados, retiraram-se amostras de café beneficiado que, após a torra e moagem, foram avaliadas por classificadores do Ministério da Agricultura. Para cada trata- 
mento, nas safras de 2001/2002, 2002/2003 e 2003/2004, foram analisados os seguintes aspectos: classificação de peneiras; renda; bebida; aspecto (bom; regular/bom; regular/mau; mau); seca (boa; regular/boa; regular; regular/má; má); cor (verde; esverdeada; verde manchada; esverdeada/manchada; esbranquiçada); fava (chato graúdo; chato ligado; bica corrida); umidade (11 a 13\% - ótima; abaixo de 10\% - regular; acima de 14\% - má); tipo (2 a 3 - excelente; 3 a 4 - bom; 4 a 5 - regular; 5 a 6 - mau; 6 a 8 - péssimo); \% de defeitos ( 0 - excelente; 1 a 5 - bom; 6 a 8 - péssimo); torração (boa; regular/boa; regular; regular/má; má); aroma (bom; regular/bom; regular; regular/mau; mau); corpo (bom; regular/bom; regular; regular/fraco; fraco); acidez (alta; pouco alta; normal; pouco baixa; baixa); amargo (baixo; normal; forte); bebida (mole; apenas mole; dura; riada; rio); conceito geral (5 - excelente; 4 ótimo; 3 - bom; 2 - regular; 1 - mau). Não se realizaram análises de qualidade de bebida na safra 2000/2001, mas se optou por apresentar, neste trabalho, os resultados dos seguintes aspectos: renda, peneira, bebida e conceito geral.

Os dados de produtividade foram submetidos a análise estatística descritiva e inferencial, com nível de significância de 5\%. Para a análise estatística descritiva, foram utilizados a média, o desvio padrão e a apresentação dos dados na forma de Boxplot. O Boxplot é representado por uma caixa delimitada pelos valores correspondentes ao primeiro quartil, mediana e terceiro quartil; a distância entre a extremidade superior e inferior da caixa representa a distância interquartílica e as extremidades dessa distância, o valor máximo e mínimo. Os outliers estão representados pelo sinal de "+" e demonstram os valores maiores que $1,5 \mathrm{vez}$ a distância interquartílica. $\mathrm{O}$ intervalo de confiança é representado pela chanfradura no meio da caixa e corresponde ao nível de significância de 5\% para a média. Na estatística inferencial, para a verificação da normalidade e da homocedasticidade dos dados, foram utilizados os testes Kolmogorov-Smirnov e Bartlett, respectivamente. Após a verificação da normalidade e homocedasticidade dos dados, utilizou-se a ANOVA; após a verificação da significância da ANOVA, empregou-se o teste de Tukey para comparações múltiplas.

\section{RESULTADOS E DISCUSSÃO}

Estão dispostos, nas Figuras 1 e 2, os valores de produtividade ao longo de 4 anos, comparando-se as diferenças entre os anos e tratamentos, respectivamente. Analisando-se os gráficos Boxplot, vê-se que houve diferenças significativas de produtividade entre os anos de condução do experimento (Figura 1A). A diferença de produtividade entre os anos pode ser explicada pela incidência da doença fúngica ferrugem (Hemileia vastatrix), que atingiu níveis de infestação acima de $80 \%$ nos anos 2001 e 2002 afetando, de forma geral, a produção dos anos subseqüentes. Outra explicação possível para tais diferenças é a bianualidade do cafeeiro que, segundo Rena $\&$ Maestri (1985) se constitui em fator significativo na cultura do café, próprio de sua natureza fisiológica, com safras altas e baixas, necessitando vegetar em um ano para produzir bem no ano seguinte. Camargo \& Camargo (2001) confirmam esta informação, afirmando que o cafeeiro leva dois anos para completar o ciclo fenológico de frutificação, ao contrário da maioria das plantas que completam o ciclo reprodutivo no mesmo ano fenológico. No presente trabalho, os anos de alta foram 2001, 2002 e 2004 e o ano de baixa foi 2003; já para os diferentes tratamentos e se analisando o Boxplot, verifica-se que não houve diferença entre os tratamentos, constatação confirmada com a comparação das médias pelo Teste de Tukey (Tabela 5).

Considerando-se padrão o tratamento referente à aplicação de fertilizantes convencionais via solo, verificaram-se perdas médias em 4 safras de 2,20, 5,5, 6,7 e 7,8\%, respectivamente para os tratamentos fertirrigação com adubos organominerais líquidos, fertirrigação com adubos altamente solúveis, adubação convencional via solo com fontes organominerais e fertirrigação com adubos convencionais, embora sem diferenças significativas (Tabela 5). A semelhança entre os tratamentos pode ser explicada pelo fato das quan-

A.

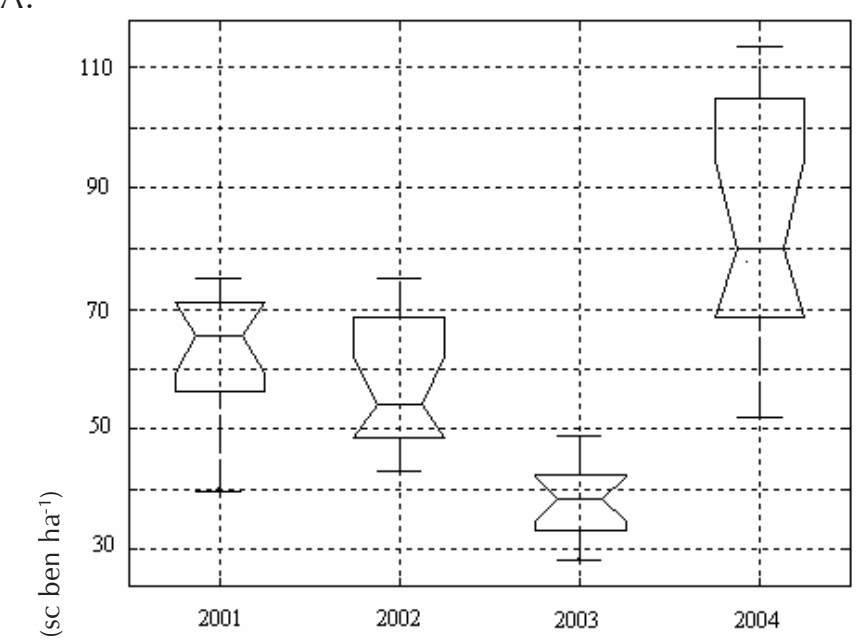

B. $\frac{\text { Tे }}{\frac{2}{2}}$

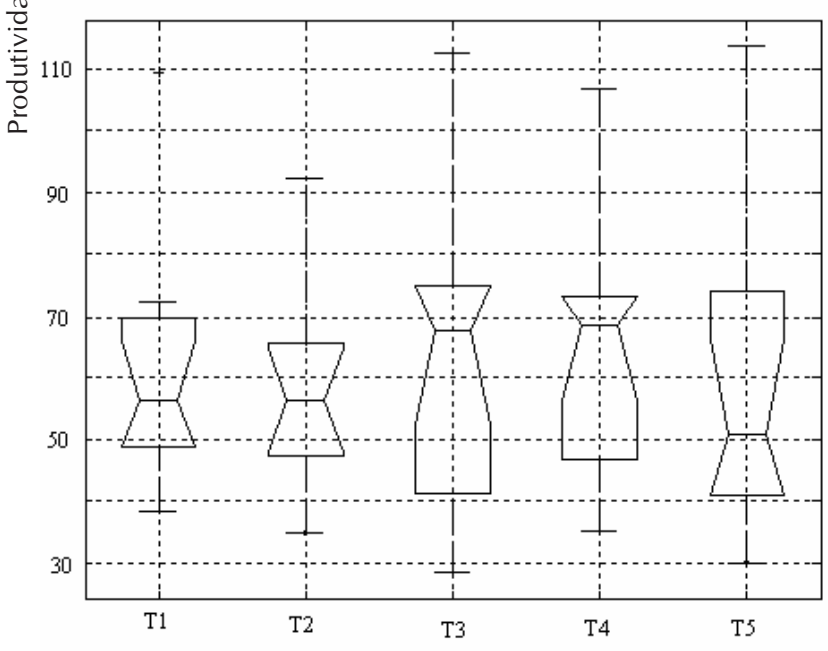

Figura 1. Boxplot dos dados de produtividade em sacas beneficiadas por hectare (sc. ben. ha ${ }^{-1}$ ) para: (A) diferentes anos do experimento $(2001,2002,2003 \mathrm{e}$ 2004) e (B) diferentes tratamentos - média dos quatro anos (T1 - Fertirrigação com adubos altamente solúveis; T2 - Fertirrigação com adubos convencionais; T3 - Fertirrigação com adubos organominerrais líquidos; T4 - Adubação convencional via solo com fontes minerais; T5 - Adubação convencional via solo com fontes organominerais) 
Tabela 5. Produtividade anual e média (sacas beneficiadas por hectare) de 4 safras para os diferentes tratamentos de fertirrigação com produtos químicos e organominerais.

\begin{tabular}{|c|c|c|c|c|c|}
\hline \multirow{2}{*}{ Tratamentos* } & \multicolumn{5}{|c|}{ Produtividade (sacas beneficiadas ha-1) } \\
\hline & 2001 & 2002 & 2003 & 2004 & Média \\
\hline $\mathrm{T} 1$ & $64,2 \mathrm{a}$ & $56,7 \mathrm{a}$ & $43,3 \mathrm{a}$ & $76,4 \mathrm{a}$ & $60,2 \mathrm{a}$ \\
\hline T2. & $60,1 \mathrm{a}$ & $54,3 \mathrm{a}$ & $41,1 \mathrm{a}$ & $79,3 \mathrm{a}$ & $58,7 \mathrm{a}$ \\
\hline T3 & $60,9 a$ & $63,0 \mathrm{a}$ & $33,4 \mathrm{a}$ & $92,0 \mathrm{a}$ & $62,3 \mathrm{a}$ \\
\hline T4 & $71,5 \mathrm{a}$ & $63,9 \mathrm{a}$ & $39,3 \mathrm{a}$ & $80,3 \mathrm{a}$ & $63,7 \mathrm{a}$ \\
\hline T5 & $57,2 \mathrm{a}$ & $49,1 \mathrm{a}$ & 33,8 a & $97,3 \mathrm{a}$ & $59,4 \mathrm{a}$ \\
\hline C.V.\% & 17,2 & 19.5 & 19,1 & 34,4 & 33,3 \\
\hline DMS (Tukey) & 29,1 & 30.0 & 13,4 & 56,5 & 44,3 \\
\hline $\begin{array}{l}\text { T1 - Fertirrigação c } \\
\text { T2 - Fertirrigação } \\
\text { T3 - Fertirrigação co } \\
\text { T4 - Adubação conv } \\
\text { T5 - Adubação conv }\end{array}$ & $\begin{array}{l}\text { adubos a } \\
\text { adubos cc } \\
\text { adubos on } \\
\text { cional via } \\
\text { cional via }\end{array}$ & 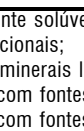 & $\begin{array}{l}\text { ais; } \\
\text { ominer }\end{array}$ & & \\
\hline
\end{tabular}

tidades dos macronutrientes fornecidas por tratamento (nitrogênio, fósforo e potássio) terem sido as mesmas, alteradas apenas a fonte desses nutrientes e a forma de aplicação. Outro aspecto a ser levado em consideração é que todos os tratamentos foram irrigados, o que contribuiu para que os fertilizantes aplicados, independentemente da fonte ou forma de aplicação, fossem aproveitados de forma semelhante pelas plantas nas parcelas. Resultados semelhantes foram obtidos por Soares et al. (2003), que estudaram o efeito de diferentes fontes de fertilizantes com fósforo, potássio e nitrogênio, na produtividade do cafeeiro, na região de Viçosa, MG, mas não encontraram diferenças significativas em termos de produtividade do cafeeiro com a aplicação de fontes solúveis e fontes convencionais de fertilizantes, apesar do custo das fontes solúveis (importadas) ter um preço 4 vezes superior ao das fontes convencionais (uréia, cloreto de potássio e superfosfato simples).

Comparando-se as análises foliares dos tratamentos (Tabela 6), não foram encontradas diferenças entre os valores dos macros e micronutrientes, o que oferece uma indicação do aproveitamento semelhante dos nutrientes nos diferentes tratamentos, comprovado pela produtividade sem diferenças significativas, ao longo de 4 anos. Confrontando-se com os valores obtidos por Bataglia et al. (2004), verifica-se semelhança entre os mesmos para cafeeiros de alta produtividade (aci- ma de 50 sacas beneficiadas $\mathrm{ha}^{-1}$ ), com os seguintes teores foliares: $32,7 \mathrm{~g} \mathrm{~kg}^{-1}$ de N, 1,7 $\mathrm{g} \mathrm{kg}^{-1}$ de P, 23,5 $\mathrm{g} \mathrm{kg}^{-1}$ de K, 12,8 $\mathrm{g} \mathrm{kg}^{-1}$ de Ca, 3,8 $\mathrm{g} \mathrm{kg}^{-1}$ de Mg, 2,2 $\mathrm{g} \mathrm{kg}^{-1}$ de S, 51,8 mg kg-1 de B, 14,5 mg kg-1 de Cu, 115,1 mg kg-1 de Fe, 99,9 mg kg-1 de $\mathrm{Mn}$, e $10,9 \mathrm{mg} \mathrm{kg}^{-1}$ de $\mathrm{Zn}$. Em relação aos valores obtidos pelos autores, que realizaram uma diagnose nutricional do cafeeiro variando a constante de sensibilidade dos nutrientes, de acordo com a intensidade e freqüência de resposta na produção, verificou-se superioridade neste trabalho nos teores foliares médios de $\mathrm{P}, \mathrm{Ca}, \mathrm{S}, \mathrm{B}, \mathrm{Mn}$ e $\mathrm{Zn}$.

$\mathrm{Na}$ Tabela 7 estão dispostos os resultados de rendimento porcentual em $\mathrm{kg}$ de café em coco ( $12 \%$ de umidade), para produzir $1 \mathrm{~kg}$ de café beneficiado para os diferentes tratamentos. Nota-se ausência de diferenças significativas entre os tratamentos, sendo possível apenas notar a diferença de rendimento entre os anos, com superioridade para os anos de 2001 e 2004, quando também foram maiores as produtividades médias dos tratamentos, com valores de 62,78 e 85,05 sacas beneficiadas $\mathrm{ha}^{-1}$, comparadas às 57,41 e 38,21 sacas beneficiadas ha-1 obtidas nos anos 2002 e 2003.

Tabela 7. Rendimento percentual em $\mathrm{kg}$ de café em coco para $\mathrm{kg}$ de café beneficiado ( $2 \%$ de umidade), para os tratamentos aplicados durante os anos de 2001 a 2004

\begin{tabular}{cccccc}
\hline Tratamento* $^{*}$ & $\mathbf{2 0 0 1}$ & $\mathbf{2 0 0 2}$ & $\mathbf{2 0 0 3}$ & $\mathbf{2 0 0 4}$ & Médias \\
\hline T1 & 52,0 & 50,6 & 49,1 & 53,0 & $51,1 \mathrm{a}$ \\
T2 & 52,1 & 50,1 & 48,0 & 53,1 & $50,8 \mathrm{a}$ \\
T3 & 51,0 & 49,1 & 47,1 & 50,0 & $49,3 \mathrm{a}$ \\
T4 & 50,6 & 48,3 & 46,0 & 50,5 & $48,8 \mathrm{a}$ \\
T5 & 49,0 & 48,6 & 48,1 & 48,9 & 48,6 \\
C.V.\% & & & & & 3,55 \\
\hline DMS (Tukey) & & & & & 3,864 \\
\hline
\end{tabular}

* T1 - Fertirrigação com adubos altamente solúveis

T2 - Fertirrigação com adubos convencionais

T3 - Fertirrigação com adubos organominerrais líquidos

T4 - Adubação convencional via solo com fontes minerais

T5 - Adubação convencional via solo com fontes organominerais

O rendimento percentual é uma variável importante a ser avaliada, quando se comparam os tratamentos irrigados e os fertirrigados. Dentre as características que afetam o rendimento, estão o tamanho e o peso das sementes. Neste ponto, é fundamental considerar a fase de expansão da membrana,

Tabela 6. Teores de nutrientes em folhas de cafeeiro, na época da granação (média de 4 anos)

\begin{tabular}{|c|c|c|c|c|c|c|c|c|c|c|c|c|}
\hline \multirow{2}{*}{ Tratamento* } & N & $\mathbf{P}$ & K & $\mathrm{Ca}$ & Mg & $S$ & $\mathrm{Na}$ & B & $\mathrm{Cu}$ & $\mathrm{Fe}$ & Mn & $\mathrm{Zn}$ \\
\hline & \multicolumn{6}{|c|}{$\mathrm{g} \mathrm{kg}^{-1}$} & \multicolumn{6}{|c|}{$\mathrm{mg} \mathrm{kg}^{-1}$} \\
\hline $\mathrm{T} 1$ & 31,2 & 2,5 & 21,4 & 17,7 & 3,3 & 3,3 & 26,0 & 149,4 & 13,0 & 126,0 & 526,0 & 22,0 \\
\hline T2 & 34,7 & 2,3 & 23,0 & 16,0 & 3,2 & 3,0 & 46,0 & 125,6 & 12,0 & 114,0 & 330,0 & 21,0 \\
\hline T3 & 31,9 & 2,9 & 19,7 & 15,8 & 3,3 & 5,0 & 27,0 & 122,4 & 12,0 & 124,0 & 818,0 & 20,0 \\
\hline T4 & 36,4 & 2,0 & 20,2 & 11,5 & 3,0 & 2,7 & 21,0 & 94,7 & 14,0 & 98,0 & 476,0 & 14,0 \\
\hline T5 & 28,1 & 2,1 & 21,8 & 15,6 & 3,4 & 2,5 & 28,0 & 113,4 & 10,0 & 101,0 & 400,0 & 19,0 \\
\hline Médias & 32,5 & 2,4 & 21,2 & 15,3 & 3,2 & 3,3 & 29,6 & 121,1 & 12,2 & 112,6 & 510,0 & 19,2 \\
\hline
\end{tabular}

* T1 - Fertirrigação com adubos altamente solúveis

T2 - Fertirrigação com adubos convencionais

T3 - Fertirrigação com adubos organominerrais líquidos

T4 - Adubação convencional via solo com fontes minerais

T5 - Adubação convencional via solo com fontes organominerais 
Tabela 8. Resultados da análise sensorial do café produzido nos diferentes tratamentos, Uberaba, MG, safras 2001/2002, 2002/2003 e $2003 / 2004$

\begin{tabular}{|c|c|c|c|c|c|c|}
\hline \multirow{2}{*}{ Safras } & \multirow{2}{*}{ Descrição } & \multicolumn{5}{|c|}{ Tratamento* } \\
\hline & & $\mathrm{T} 1$ & T2 & T3 & T4 & T5 \\
\hline \multirow{4}{*}{$2001 / 2002$} & Renda (kg) & 20,0 & 20,5 & 20,0 & 21,0 & 21,0 \\
\hline & $\%$ pen $>16$ & 77 & 78 & 65 & 85 & 72 \\
\hline & Bebida & Dura & Dura & Ap. Mole & Dura & Dura \\
\hline & Conceito Geral & 1,0 & 1,0 & 2,5 & 1,5 & 1,0 \\
\hline \multirow{4}{*}{$2002 / 2003$} & Renda (kg) & 22,8 & 18,7 & 18,8 & 19,5 & 17,2 \\
\hline & $\%$ pen $>16$ & 69,0 & 66,0 & 69,4 & 54,8 & 70,6 \\
\hline & Bebida & Apenas Mole & Dura & Apenas mole & Apenas Mole & Apenas Mole \\
\hline & Conceito Geral & 3,0 & 2,0 & 3,0 & 2,5 & 3,0 \\
\hline \multirow{4}{*}{$2003 / 2004$} & Renda (kg) & 20,8 & 18,9 & 18,5 & 19,8 & 19,5 \\
\hline & $\%$ pen $>16$ & 79 & 56 & 59 & 57 & 45 \\
\hline & Bebida & Dura & Dura & Dura & Ap. Mole & Dura \\
\hline & Conceito Geral & 3,0 & 3,0 & 2,5 & 3,5 & 3,5 \\
\hline
\end{tabular}

denominada pergaminho, que terá influência direta no crescimento do fruto. Rena \& Maestri (1986) relataram que esta fase é extremamente sensível ao déficit hídrico, pois é quando o tamanho do endocarpo (pergaminho) delimita o tamanho da semente. Soares (2001), em experimento semelhante, avaliou a produtividade e o rendimento pós-colheita de tratamentos sem irrigação, irrigados e adubados de forma convencional, e irrigados e fertirrigados com fontes convencionais e com as de alta solubilidade. Os rendimentos foram de 45,9 a 50,2\%, com diferenças significativas entre os tratamentos irrigados e o não irrigado, porém sem diferenças dentro dos tratamentos irrigados e fertirrigados. Com relação à produtividade, também não se verificaram diferenças significativas entre os tratamentos irrigados e fertirrigados. Uma constatação interessante do autor foi que, apesar de não ter havido diferenças significativas de produtividade entre as fontes de fertilizantes, quando foram utilizadas fontes de alta solubilidade em fertirrigação, o custo ficou $428 \%$ superior quando comparado com a utilização de fontes convencionais (uréia, cloreto de potássio e superfostato simples) em fertirrigação.

Em relação à qualidade do café, após a análise sensorial (Tabela 8), verifica-se ausência de grandes diferenças entre os tratamentos, com ligeira superioridade para o tratamento fertirrigação com adubos organominerais líquidos. Nota-se, também, a ocorrência de significativa melhoria nos resultados de qualidade para praticamente todos os tratamentos na safra 2002/2003, fato explicado pela melhoria no processamento do café, inicialmente com secagem exclusiva em terreiro de terra batida e, posteriormente, com a instalação de secadores, quando então foi possível a obtenção de café de melhor bebida.

Na safra 2002/2003, apenas o tratamento fertirrigação com adubos convencionais apresentou bebida de pior qualidade que os demais (bebida dura). Na safra 2003/2004, o melhor tratamento, em termos de qualidade de bebida, foi o relativo à aplicação de fontes químicas, de forma convencional no solo. Durante a condução do experimento em 4 safras, não foi possível identificar a influência das fontes de fertilizantes na qualidade da bebida do café. Com relação ao conceito geral, não se chegou a um valor maior que três e meio, fato este atribuído à desuniformidade na maturação dos frutos de café, quando comparado com uma lavoura de café nas mesmas condições, porém cultivada em condições de sequeiro, com conceitos superiores aos obtidos nos tratamentos irrigados e fertirrigados. Segundo Mantovani \& Soares (2003), são escassos, na literatura, os estudos sobre o efeito da irrigação e fertirrigação na qualidade final da bebida do café, não havendo informações conclusivas que permitam a associação da irrigação com a qualidade de bebida e qualidade física do café.

\section{CONCLUSÕES}

1. As fontes de fertilizantes utilizadas, tanto em fertirrigação quanto em aplicação convencional, no solo, não apresentaram diferenças significativas em termos de produtividade.

2. Pelo fato das fontes convencionais de fertilizantes apresentarem produtividades equivalentes às fontes de alta solubilidade, é possível concluir que é viável a utilização das mesmas em fertirrigação, devido ao seu custo mais baixo, desde que se tomem os devidos cuidados com a manutenção do sistema de irrigação por gotejamento.

3. Com relação à qualidade final do café não se verificaram diferenças significativas entre os tratamentos.

\section{LITERATURA CITADA}

AGRIANUAL - Anuário da Agricultura Brasileira. São Paulo: FNP Consultoria e Comércio, 2002. 536p. 
Antunes, R.C.B.; Rena, A.B.; Mantovani, E.C.; Alvarenga, A.P.; Costa, L.C.; Dias, A.S.C. Influência da fertirrigação em nitrogênio e potássio nos componentes vegetativos do cafeeiro arábica em formação. In: Simpósio de Pesquisa dos Cafés do Brasil, 1, 2000, Poços de Caldas. Anais... Poços de Caldas: Embrapa-Café, 2000. Cd Rom.

Bataglia, O.C.; Quaggio, J.A.; Santos, W.R. dos; Abreu, M.F. de. Diagnose nutricional do cafeeiro pelo DRIS variandose a constante de sensibilidade dos nutrientes de acordo com a intensidade e freqüência de resposta na produção. Bragantia, Campinas, v.63, n.2, p.253-263, 2004.

Camargo, A.P.; Camargo, M.B.P. Definição e esquematização das fases fenológicas do cafeeiro arábica nas condições tropicais do Brasil. Bragantia, Campinas, v.60, n.1, p.65-68, 2001.

Camargo, A.P.; Pereira, A.R.P. Agrometeorology of coffee crop. Geneve: WMO, 1994. 53p. Bulletin, 58.

CONAMA - Conselho Nacional do Meio Ambiente. Resolução Normativa n. 020, 18 jun. 1986.

Costa, E.F.; França, G.E.; Alves, V.M.C. Aplicação de fertilizante via água de irrigação. Informe Agropecuário, Belo Horizonte, v.12, n.129, p.63-68, 1986.

Frizzone, J.A; Zanini, J.R.; Paes, L.A.D.; Nascimento, V.M. Fertirrigação mineral. Ilha Solteira: UNESP, 1985. 31p. Boletim Técnico 2

Hernandez, F.B.T. Potencialidades da fertirrigação. In: Simpósio Brasileiro sobre Fertilizantes Fluidos, 1993, Piracicaba. Anais... Piracicaba: ESALQ, 1993. p.199-210.

Loomis, R.S.; Connor, D.J. Crop ecology: Productivity and management in agricultural systems. Cambridge: Cambridge University Press, 1992, 520p.

Mantovani, E.C.; Soares, A.R. Irrigação do cafeeiro: Informações técnicas e coletânea de trabalhos. Viçosa: Associação dos Engenheiros Agrícolas de Minas Gerais: UFV, DEA, 2003, 260p. Boletim Técnico, 8

Monteith, J.L. Evaporation and environment. Symposium of Society of Experimental Biology, London, v.19, p.205-234, 1965.
Pizarro, F. Riegos localizados de alta frequencia: goteo, microaspersion, exudacion. Madri: Mundi-Prensa, 1990, 470p.

Rena, A.B.; Maestri, M. Fisiologia do cafeeiro. Informe Agropecuário, Belo Horizonte, v.11, n.126, p.26-40, 1985.

Santinato, R.; Fernandes, A.L.T. Cultivo do cafeeiro irrigado em plantio circular sob pivô central. 1ed. Belo Horizonte: $\mathrm{O}$ lutador, 2002. 251p.

Santinato, R.; Fernandes, A.L.T.; Fernandes, D.R. Irrigação na cultura do café. Campinas: Arbore Agrícola e Comércio Ltda. 1.ed, 1996. 146p

Silva, A.L. da; Faria, M.A. de; Reis, R.P. Viabilidade técnicoeconômica do uso do sistema de irrigação por gotejamento na cultura do cafeeiro. Revista Brasileira de Engenharia Agrícola e Ambiental, Campina Grande, v.7, n.1, p.37-44, 2003.

Smith, M. Report on the expert consultation on procedures for revision of FAO guidelines for predictions of crop water requirements. Rome: FAO, 1991, 45p.

Soares, A.R. Irrigação, fertirrigação, fisiologia e produção em cafeeiros adultos na região da zona da mata de Minas Gerais. Viçosa: UFV, 2001. 84p. Dissertação Mestrado

Soares, A.R.; Mudrik, A.S.; Silva, T.C.; Mantovani, E.C. Estudo sobre a utilização de distintas fontes de nitrogênio e potássio na produtividade dos cafeeiros irrigados e fertirrigados (resultado de três colheitas). In: Simpósio de Pesquisa dos Cafés do Brasil, 3, 2003, Porto Seguro. Anais. Porto Seguro: Embrapa-Café, 2003. Cd Rom.

Teixeira, A.A.; Gomes, F.P.; Pereira, L.S.P.; Moraes, R.S.; Castilho, A.A. A influência de grãos verdes com ligas com cafés de bebida mole, Boletim Técnico do IBC, v.3, p.3-15, 1970.

van Raij, B.; Fernandes, D.R.; Oliveira, E.G.; Malavolta, E. Café. In: van Raij, B.; Cantarella, H.; Quaggio, J.A.; Furlani, A.M.C. (eds.). Recomendações de adubação e calagem para o Estado de São Paulo. 2.ed. Campinas: IAC, 1997. p.97101. Boletim Técnico, 100 